\title{
ALTERNATIVE POSSIBILITIES OF DETECTION OF MANIPULATION WITH THE ACCOUNTING DATA
}

Ladislav Kabat

School of public administration, Bratislava, Slovakia

Stanislav Filip

School of public administration, Bratislava, Slovakia

(C) MESTE NGO

JEL Classification: C1, M4, Y90

\begin{abstract}
The fraud reporting and data manipulation is discussed across the various scientific fields - in economy, finance, sociology and many others. Particularly, the economic and finance data are under the strong scrutiny. In literature we can find extensive discussion on the creative accounting, which is considered as the source of the intensive data manipulation. It is pointed on the fact that the managers may adopt various methods to manipulate the financial statements of their firms to show their higher/better performance and to receive the higher managerial earnings. The Benford law as a statistical tool is illustrated as a possible tool in detecting this problem.
\end{abstract}

Key words: accounting data, creative accounting, data manipulation, Benford Law

\section{INTRODUCTION}

Statistical information plays an important role in decision making processes on all managerial levels. It is on the macroeconomic level, as well as on the level of individual companies. The qualified managerial decision could be derived only on the base of the reliable information. This is the reason why researchers and managers try to work with the highest quality data. This is true particularly with economic and financial data, which mirror the activity of individual companies. Various legislative tools and methodological guidelines

Address of the corresponding author:

Ladislav Kabat

棒: ladislav.kabat@vsemvs.sk have been developed to assist the companies in generation and processing their accounting data according the internationally adopted standards. Among them, the international financial report standards, as well as the methodological specifications of the national accounts could be mentioned.

Despite all these efforts, the increasing number of various fraud reports and manipulations with accounting data is reported over last years, many of them with serious negative impacts on international economies. As an example the following cases could be recalled.

The Lehman Brothers (2008) with the Global financial services firm hid over $\$ 50$ billion of toxic assets in loans disguised as sales. They created the impression Lehman had $\$ 50$ billion more cash 
and $\$ 50$ billion less in toxic assets than it really did. The Lehman Brothers which was ranked the number 1 as the most admired securities firm by Fortune magazine in 2007, went bankrupt.

Bernie Madoff Scandal (2008) and his Investment Securities LLC, the Wall Street investment firm tricked investors out of $\$ 64.8$ billion through the largest Ponzi scheme in history. Madoff was sentenced to 150 years in prison and $\$ 170$ billion of restitution.

Indian IT services accounting firm Satyam (2009) falsely boosted revenue by $\$ 1.5$ billion. The chairman Ramaling Raju falsified revenues, margins and cash balances. He admitted the fraud in a letter to the company's board of directors. Raju and his brother charged with breach of trust, conspiracy, cheating and falsification of records. Finally they have been released after the Central Bureau of Investigation failed to file charges on time.

Over the last years, many smaller scandals, with serious direct negative consequences on national and world economies have been reported. The indirect negative consequences through the shadow economy and tax avoidance are observed as well.

The statisticians, accounting and IT experts intensively work on the new approaches, which would help to identify the fraud accounting operations before the infiltrated or falsified data are archived into the officially recognized statistical databases.

Our paper presents the selected methodological tools enabling to check the quality of the data of the larger information data sets.

Namely, we present an alternative approach to the data quality checking, known as Benford's Law, which in certain situations could be an important tool for detecting the distorted statistical and accounting data.

\section{LITERATURE OVERVIEW}

The fraud reporting and data manipulation is discussed across the various scientific fields - in economy, finance, sociology and many others. Particularly, the economic and finance data are under the strong scrutiny. In literature we can find extensive discussion on the creative accounting, which is considered as the source of the intensive data manipulation. It is pointed on the fact that company management may adopt various methods to change the financial statements to show the improved performance of the company one of them is creative accounting.

Creative accounting is the manipulation of financial numbers, usually within the law frame and accounting standards, but also very much against the spirit of the law and not providing the true information on the company under discussion. By Gosh (2010) the key attacks from creative accounting are concentrated manipulation with data through:

- Calculation of premature or fictitious revenue

- Aggressive Capitalization and Extended Amortization Policies

- Misreported Assets and Liabilities, and

- Problems with Cash-flow Reporting.

All of the above indicated acts may cause serious damages to the companies, institutions, owners and business partners. It is the reason why they should be detected and prosecuted.

According the businessdictionary.com accounting fraud is defined as: "The intentional misrepresentation or alteration of accounting records regarding sales, revenues, expenses and other factors for a profit motive such as inflating company stock values, obtaining more favorable financing or avoiding debt obligations. Employees who commit accounting fraud at the request of their employers are subject to personal criminal prosecution". (businessdictionary.com, n.d.)

The identification of the intentionally improper manipulation with the data is not an easy task, because it could be covered by the top managers and their interest to present their economic results in the best way and to get the highest managerial earnings. An interesting study was done by Henselmann, Ditter and Scherr (2013), according whom "...the objective of financial accounting is to provide an aggregate reliable and verifiable view of financial and economic performance to stakeholders by translating business transactions into accounting numbers. Given that accounting numbers serve as the basis for stakeholders' decisions or for determining compensations, 
managers have diverse incentives to manipulate earnings...".

To deal with this problem, the authors are proposing the application of the extensible business reporting language - XBRL, which is based on the generally accepted accounting principles applied in USA. More details could be find in Homer (2008), Mahoney and White (2007) and IFRS Foundation (2013).

In order to identify or even to prevent the fraudulent acting the responsible managers can adopt some specific statistical tools, which can signal the fraud attempts at very beginning. The various measures and approaches have already been developed and applied in managerial and checking practices. One of them is based on the empirically derived knowledge on the statistical incidence of the numerical figures on specific positions.

The Benford's Law is an empirically derived and validated rule according which the numerical data starting with an arbitrary figure of $1,2, \ldots, 9$ occur in large size data files with a certain, exactly defined frequency. The first attention to this fact was studied by Newcomb (1881). This regularity was in 1938 confirmed by Benford (1938).

According the Benford's Law the frequency of appearance the numerically defined data beginning with figure $\mathbf{d}(\mathrm{d}=1,2, \ldots, 9)$ in sufficiently large data sets is defined by the formula:

$F(d)=\operatorname{LOG}(1+1 / d)$

The situation is presented in Table 1.

Table 1 Frequency of appearance the numbers with the first digit $\boldsymbol{d}(\%)$

\begin{tabular}{|c|c|c|}
\hline First & \multicolumn{2}{|c|}{ Frequency of appearance } \\
\hline $\mathbf{d}$ & $\boldsymbol{F ( d ) = L O G ( 1 + 1 / d )}$ & in $\%$ \\
\hline 1 & 0.3010 & 30.10 \\
\hline 2 & 0.1761 & 17.61 \\
\hline 3 & 0.1249 & 12.49 \\
\hline 4 & 0.0969 & 9.69 \\
\hline 5 & 0.0792 & 7.92 \\
\hline 6 & 0.0669 & 6.69 \\
\hline 7 & 0.0580 & 5.80 \\
\hline 8 & 0.0512 & 5.12 \\
\hline 9 & 0.0458 & 4.58 \\
\hline Total & $\mathbf{1}$ & $\mathbf{1 0 0}$ \\
\hline
\end{tabular}

The Benford's frequency distribution is graphically presented on Fig. 1. It is evident that the frequency of appearance of numerical data according their first digit differs significantly. While numbers starting with digit 1 occur with frequency $30.10 \%$, the numbers starting with digit 9 appear with only $4.58 \%$ frequency.

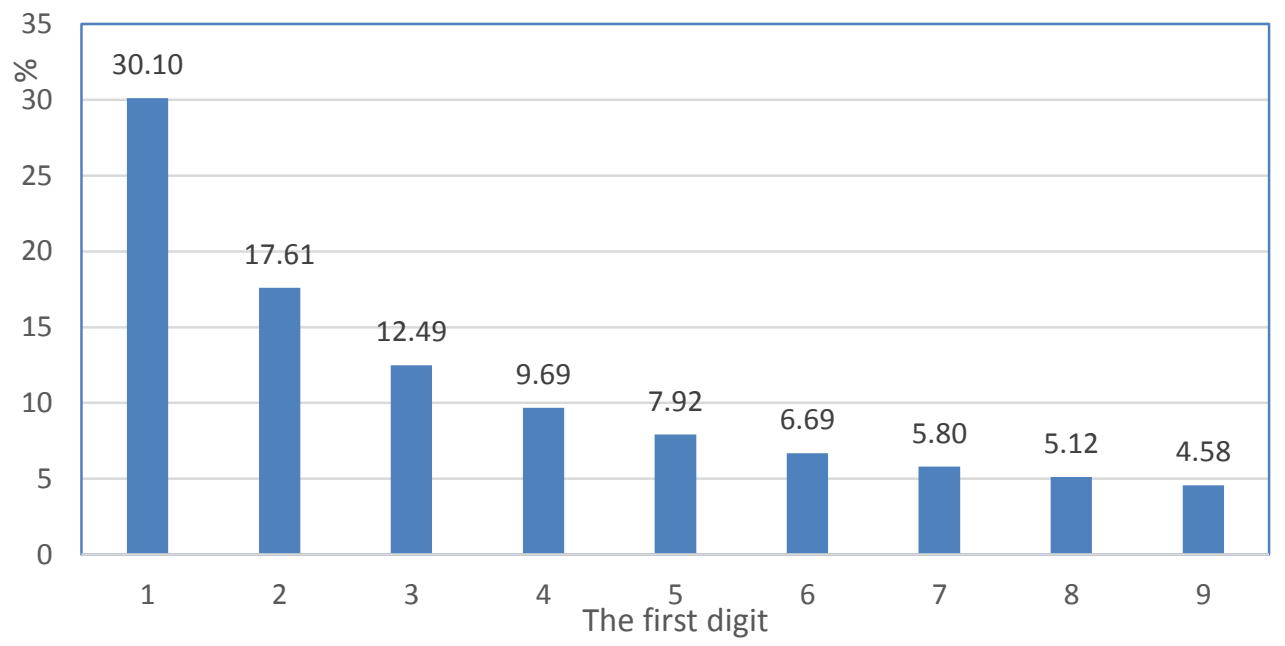

Fig. 1 Frequency of appearance the numbers with the first digit $\boldsymbol{d}(\%)$

In accordance with the basic rules of probabilistic operations it can be shown that numerical data beginning with the digits 1 or 2 occur in the studied group with frequency

$F(1$ or 2$)=F(1)+F(2)=30.10+17.61=47.71 \%$
This means they would represent nearly half of the studied data. Analogously, numbers beginning with the digits 8 or 9 appear totally only with frequency $9.69 \%$. Similarly, it is possible to construct frequency filters for testing frequencies 
of occurrence of numbers in various combinations of first digits. These and the other tests could be incorporated into specific procedures for checking the regularity of frequencies in appearance of data in the referred data sets.

In analogy with the frequency distribution of the data according the first digit, such empirically derived regularities are valid also for the frequency appearance of the digit on the second, third, and consequent positions.

According to equation (1) it could be calculated that numerical data beginning with a pair of digits
"11" occur in a large data file with frequency $3.78 \%$, the number starting with a pair of digits "12" occur with frequency $3.48 \%$ and those beginning with a pair of digits "19" occur only with a probability of $2.23 \%$. By simple procedure we can find that the frequency of occurrence of numbers that starts with any of the two digits 10 , $11,12, \ldots, 18$ or 19 is equal to $30.01 \%$, which is simply equal to the frequency of occurrence of data starting with digit 1 . These calculations, as well as some more sophisticated could be derived from the data in Table 2.

Table 2 Frequency of appearance the numbers with figures $\boldsymbol{d}_{1} \boldsymbol{d}_{2}$ at the first and the second positions

\begin{tabular}{|l|c|c|c|c|c|c|c|c|c|c|r|}
\hline $\mathrm{d}_{1} \quad \mathrm{~d}_{2>}$ & 0 & 1 & 2 & 3 & 4 & 5 & 6 & 7 & 8 & 9 & $\mathrm{~F}\left(\mathrm{~d}_{1}\right)$ at $1^{\text {st }}$ \\
\hline 1 & 0.041 & 0.038 & 0.035 & 0.032 & 0.030 & 0.028 & 0.026 & 0.025 & 0.023 & 0.022 & 0.3010 \\
\hline 2 & 0.021 & 0.020 & 0.019 & 0.018 & 0.018 & 0.017 & 0.016 & 0.016 & 0.015 & 0.015 & 0.1761 \\
\hline 3 & 0.014 & 0.014 & 0.013 & 0.013 & 0.013 & 0.012 & 0.012 & 0.012 & 0.011 & 0.011 & 0.1249 \\
\hline 4 & 0.011 & 0.010 & 0.010 & 0.010 & 0.010 & 0.010 & 0.009 & 0.009 & 0.009 & 0.009 & 0.0969 \\
\hline 5 & 0.009 & 0.008 & 0.008 & 0.008 & 0.008 & 0.008 & 0.008 & 0.008 & 0.007 & 0.007 & 0.0792 \\
\hline 6 & 0.007 & 0.007 & 0.007 & 0.007 & 0.007 & 0.007 & 0.007 & 0.006 & 0.006 & 0.006 & 0.0669 \\
\hline 7 & 0.006 & 0.006 & 0.006 & 0.006 & 0.006 & 0.006 & 0.006 & 0.006 & 0.006 & 0.005 & 0.0580 \\
\hline 8 & 0.005 & 0.005 & 0.005 & 0.005 & 0.005 & 0.005 & 0.005 & 0.005 & 0.005 & 0.005 & 0.0512 \\
\hline 9 & 0.005 & 0.005 & 0.005 & 0.005 & 0.005 & 0.005 & 0.005 & 0.004 & 0.004 & 0.004 & 0.0458 \\
\hline $\mathrm{F}\left(\mathrm{d}_{2}\right)$ at 2 $2^{\text {nd }}$ & 0.120 & 0.114 & 0.109 & 0.104 & 0.100 & 0.097 & 0.093 & 0.090 & 0.088 & 0.085 & 1.0000 \\
\hline
\end{tabular}

Graphical comparison of two distributions frequency occurrence of data according the first and second position digits is shown on Fig. 2. E.g., it could be estimated that data with the first digit
"1" will appear with $31.01 \%$ frequency, while data with the second digit " 1 " will appear with $11.4 \%$ frequency only.

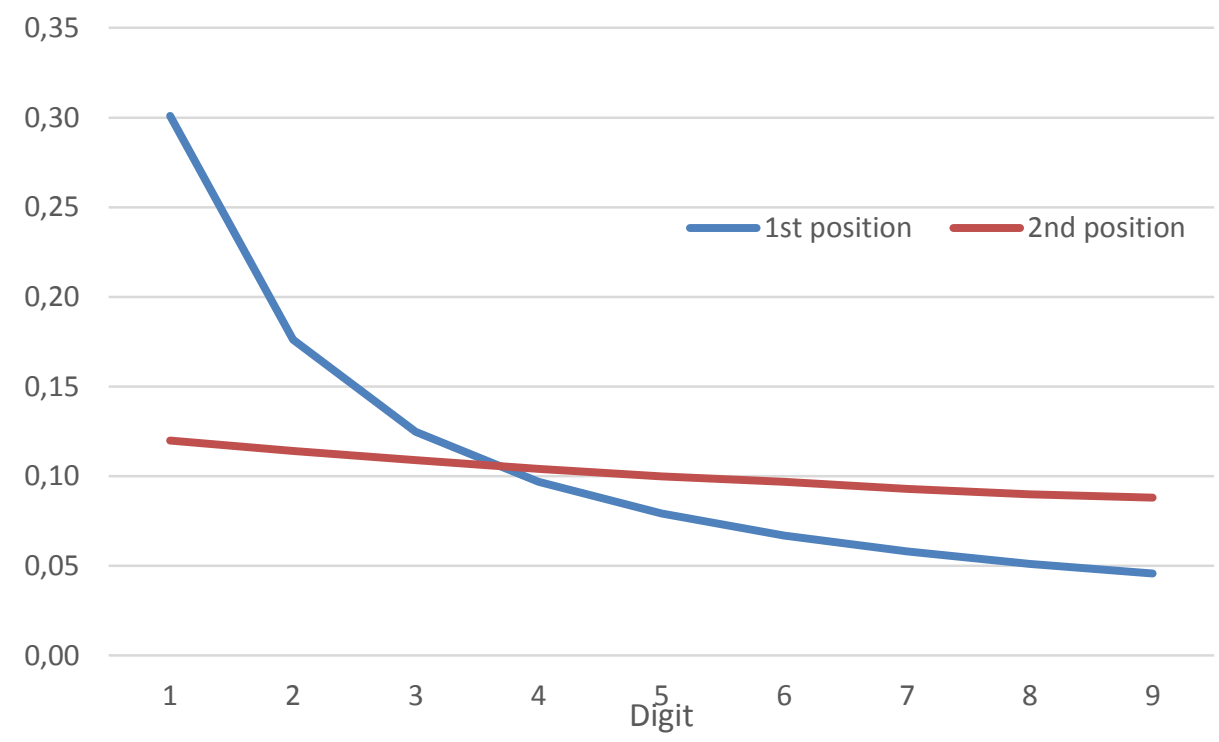

Fig. 2 Frequency of appearance the numbers with $\boldsymbol{d}_{1}$ at the $1^{\text {st }}$ and $\boldsymbol{d}_{2}$ at the $2^{\text {nd }}$ positions in $\%$ 
For proper application of the referred testing procedures should be noted that Benford's law has general validity for any data sets, regardless of content which these numbers represent. An important prerequisite for the reliable application of this procedure however is that the value of the data examined are not explicitly limited (setting their minimum and maximum values), or otherwise externally influenced. Examples of data files which are not following the Benford's distribution are the data on values expressing the social benefits defined by legislative measure, data on wage tariffs, which are defined by the special legislation or negotiation by trade union and employers, data on economic results of enterprises that are functionally interdependent (as auxiliary variables - profitability, productivity per worker, or per unit of time, etc.). We should be also careful when working with data, which are directly defined by legislative standards or any internally applied rules (e.g. jubilee benefits, social needs compensations, various health care entitlements, duty travel compensation, etc.).

\section{RESULTS}

The economic problems that currently deal with almost all countries of the European Union require intensive mobilization of all domestic resources. One of the approaches that meet these requirements includes consistent monitoring of tax evasion. Particular attention is paid to identification of the improperly or even fraudulently reported balance sheets for calculating tax returns, which are frequently identified with the creative accounting and tax optimization. These methodologies are almost regularly offered as a part of the accounting education at universities.

The natural question, when dealing with the tax evasion and fraudulent tax reporting, is who are the main actors of this game? Based on extended literature sources there are several group of actors, who in varying degree with different weight participate, encourage or support the creative accounting and fraudulent reporting. Among them are:

- Managers of businesses who are
interested in short-term business
successes,
Investors seeking the most effective
increase of their financial resources,

Employees involved in recovering company's profit, and

- Owners (shareholders) interested in short-term profits, but also in better presentation of their businesses.

From 90s is evident progress toward intensive development support control instruments in the field of accounting and auditing. The extraordinary development has made forensic accounting as a separate component of the methodology of accounting and auditing.

Given the complexity of the accounting agenda the forensic accounting is forced to apply the new modern statistical methods and software applications. Possibility of simultaneous controls of the large information files with complex multilevel cross checking of these files has opened new and wide possibilities for increasing the effectiveness of such controls.

Experience in this area varies from country to country. Applications of the most sophisticated methods in the auditing practice are known in the U.S. where, for example, the methodology of data quality assessment based on Benford law became an organic part of the official audit procedures. Despite this fact, however, these exact tools are not generally accepted and considered as the decisive checking tools. The results obtained through such tools must be analyzed also by the classical qualitative analysis. Equally cautious on general application of the Benford's methodology is also the academic literature.

The deeper analysis of the accounting data according to Benford's methodology will be presented on real accounting data generated by custom administration. This account contained 5 000 items. Results of the analysis of this data set in terms of their frequency distribution according the Benford's law are presented in Table $\mathbf{3}$ in in following order:

The first column - the first digit of the numerical data under study $\mathbf{d}$

The second column - expected frequency of occurrence of the data $\mathrm{Ti}$

The third column - empirical frequency of occurrence of the data $\mathbf{E i}$

The fourth column - difference of frequencies $\mathbf{T i}$ and $\mathbf{E i}$ 
Table 3 Custom statistics data - 5000 numbers

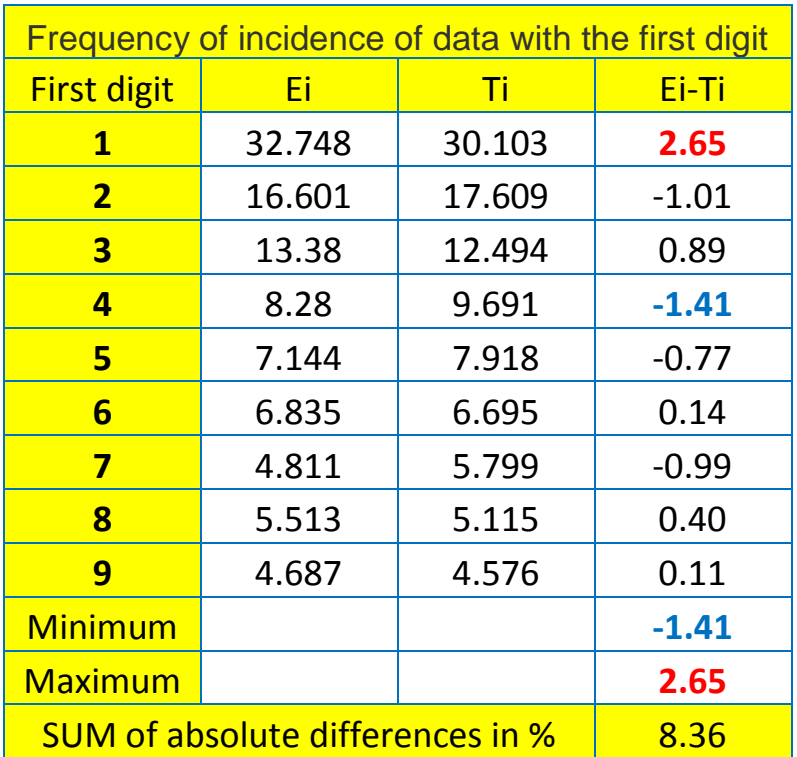

As shown in the table there are some differences between expected and empirical frequencies in occurrence the numerical data on accounts under consideration. The data starting with digit 1 represent $32,86 \%$ of the total number of numerical data, which is $2.76 \%$ above the expected frequency, in case of data starting with digit 2 the difference is $1.04 \%$. The sum of these deviations for all first digits in absolute values reaches $8.47 \%$. The largest positive deviation of empirical and expected frequency was identified at numerical data starting with digit 4, while the largest negative deviation is connected with data containing figure 1 on the first position.

The frequency occurrence of the data in this file has been examined also in terms of consistency with the frequency according the second digit. The results are summarized in Table. 4
Table 4 Custom statistic data - 5000 numbers

\begin{tabular}{|r|r|r|r|r|}
\hline Digit & \multicolumn{1}{l|}{ Ei } & \multicolumn{1}{l|}{$\mathrm{Ti}$} & \multicolumn{1}{l|}{$\mathrm{Ei}-\mathrm{Ti}$} & \multicolumn{1}{l|}{ Abs } \\
\hline 0 & 12.34 & 11.97 & 0.373 & 0.373 \\
\hline 1 & 11.21 & 11.39 & -0.181 & 0.181 \\
\hline 2 & 10.92 & 10.88 & 0.042 & 0.042 \\
\hline 3 & 9.95 & 10.43 & 0.479 & 0.479 \\
\hline 4 & 9.49 & 10.03 & 0.543 & 0.543 \\
\hline 5 & 9.93 & 9.67 & 0.266 & 0.266 \\
\hline 6 & 9.51 & 9.34 & 0.171 & 0.171 \\
\hline 7 & 8.27 & 9.04 & 0.761 & 0.761 \\
\hline 8 & 8.96 & 8.76 & 0.205 & 0.205 \\
\hline 9 & 9.41 & 8.50 & 0.908 & 0.908 \\
\hline Total & 100 & 100 & 0 & 3.929 \\
\hline
\end{tabular}

In the studied data set there are approximately $3.9 \%$ of the data which are not consistent with expected distribution. The highest rate of the noncomplying data is linked to those starting with figures $9(-0.908)$ and $7(+0.761)$. There is a natural question - how important or negligible these deviations are?

More detailed applications could be found in Kabat, Siller, and Majkova (2014), where some selected data of the balance sheets of the Slovak firms according their NACE structure are presented.

\section{CONCLUSION}

The above presented case illustrate that the introduction of reliable information support significantly improves the possibilities for checking the quality of accounting information. The Benford's methodology, as well as the EBRL applications, could serve as an efficient starting point for dealing with the problem of manipulation with the accounting data.

\section{WORKS CITED}

Benford, F. (1938). The law of anomalous numbers. Proceedings of the American Philosophical Society, 78(4), 551-572. Retrieved from http://www.jstor.org/discover/10.2307/984802?sid=21104958540951\&uid=4\&uid=2129\&uid=2 \&uid $=70$

businessdictionary.com. (n.d.). Accounting fraud. Retrieved 10 12, 2014, from BusinessDictionary.com: http://www.businessdictionary.com/

Gosh, S. (2010). Creative Accounting: A Fraudulent Practice Leading to Corporate Collapses. Research and Practice in Social Sciences, 6(1), 1-15. Retrieved from http://www.researchandpractice.com/articles/5-2/ghosh-1.pdf 
Henselmann, K., Ditter, D., \& Scherr, E. (2013, 07 24). Irregularities in Accounting Numbers and Earnings Management - A Novel Approach Based on SEC XBRL Filings. Retrieved from SSRN: http://papers.ssrn.com/sol3/papers.cfm?abstract_id=2297355

Homer, B. (2008). XBRL US GAAP Taxonomy Preparers Guide. XBRL US, Inc. Retrieved from http://xbrl.us/documents/preparersguide.pdf

IFRS, F. (2013). The IFRS Taxonomy Illustrated. London, UK: IFRS Foundation. Retrieved from http://www.ifrs.org/XBRL/Resources/Documents/ITI\%27s\%202013/ITI_2013_byFS_complete. pdf

Kabat, L., Siller, H., \& Majkova, M. (2014). The Benford Law and its applications. Kriminalistik, 248. Retrieved from http://www.kriminalistik.de/ausgabe/inhalt-der-ausgabe-oktober-2014\#Artikel7

Mahoney, L., \& White, C. (2007). Creating XBRL Instance Documents in Excel. The CPA Journal online.

Newcomb, S. (1881). Note on the frequency of use of the different digits in natural numbers. American Journal of Mathematics, 4(1), 39-40.

Received for publication:

30.11 .2014

Accepted for publication:

30.12.2014

\section{How to cite this article?}

Style - APA Sixth Edition:

Kabat, L., \& Filip, S. (2015, Jan 15). Alternative possibilities of detection of manipulation with the accounting data. (Z. Čekerevac, Ed.) MEST Journal, 3(1), 170-176. doi:10.12709/mest.03.03.01.18

Style - Chicago Fifteenth Edition:

Kabat, Ladislav, and Stanislav Filip. 2015. "Alternative possibilities of detection of manipulation with the accounting data." Edited by Zoran Čekerevac. MEST Journal (MESTE) 3 (1): 170-176. doi:10.12709/mest.03.03.01.18.

Style - GOST Name Sort:

Kabat Ladislav and Filip Stanislav Alternative possibilities of detection of manipulation with the accounting data [Journal] // MEST Journal / ed. Čekerevac Zoran. - Belgrade : MESTE, Jan 15, 2015. 1 : Vol. 3. - pp. 170-176.

Style - Harvard Anglia:

Kabat, L. \& Filip, S., 2015. Alternative possibilities of detection of manipulation with the accounting data. MEST Journal, 15 Jan, 3(1), pp. 170-176.

Style - ISO 690 Numerical Reference:

Alternative possibilities of detection of manipulation with the accounting data. Kabat, Ladislav and Filip, Stanislav. [ed.] Zoran Čekerevac. 1, Belgrade : MESTE, Jan 15, 2015, MEST Journal, Vol. 3, pp. 170176. 